\title{
Sağlık Bilimlerinde Alanında Öğrenim Gören Üniversite Öğrencilerinin İnterdisipliner Ekip Çalışmasına Bakışının İncelenmesi
}

\author{
Hatice Abaoğlu ${ }^{1}$, Özge Buket Cesim ${ }^{1}$, Sinem Kars ${ }^{1}$, Semin Akel ${ }^{1}$ \\ ${ }^{1}$ Hacettepe Üniversitesi, Să̆lık Bilimleri Fakültesi, Ergoterapi Bölümü, Ankara
}

\begin{abstract}
Özet
Amaç: Bu araştırmanın amacı, sağlık bilimleri alanında öğrenim gören üniversite öğrencilerinin interdisipliner ekip çalışmasına bakış açıllarını değerlendirmekti.

Gereç ve Yöntem: Araştırmaya sağlık bilimleri alanında öğrenim gören 18-25 yaş aralığında 265 üniversite öğrencisi katıldı. Bireylerin, yaş, cinsiyet, bölüm ve öğrenim gördükleri sınıfi içeren demografik bilgileri kaydedildi. Araştırmada veri toplama aracı olarak İnterdisipliner Eğitim Algısı Ölçeği’nden uyarlanarak araştırmacılar tarafindan oluşturulan 'İnterdisipliner Çalışma Anketi' kullanıldı.

Bulgular: Çalışmanın sonucunda bireylerin çoğunun, interdisipliner çalışmanın ne anlama geldiğini bildiği ve yararlı olacağını düşündüğü görüldü. Katılımcılar, büyük oranda kendi meslek grubunun ilişkide olabileceği diğer meslek gruplarıyla ilgili bilgisinin olduğunu, diğer meslek gruplarıyla uygulama ve saha çalışması yapmak istediğini ve çözemediği bir problemi başka meslek gruplarına danışmaktan kaçınmadığını belirtti. Bireylerin, çoğunlukla mesleğindeki kişilerin kendilerini diğer meslek gruplarından üstün görmedikleri, onlarla iyi ilişkide ve etkileşim halinde oldukları, onların beceri ve katkılarını anlamaya çaba gösterdikleri, bilgi ve kaynak paylaşmayı istediklerini düşündükleri tespit edildi. Buna karşın bireylerin çoğu, mesleğindeki kişilerin iyi eğitimli olduklarını düşünürken mesleki yetkili ve otonomi konusunda kısttll1kkları olduğu, diğer meslekten kişilerin kendi mesleği hakkında bilgi sahibi olmadığı görüşündeydi.
\end{abstract}

Sonuç: Sonuçlar doğrultusunda, sağlık bilimleri alanında öğrenim gören öğrencilerin interdisipliner çalışmayı önemli ve yararlı buldukları görülmüştür. Bireylerin mezuniyet sonrasında yetkililik, otonomi ve birlikte çalıştı̆̆ meslek gruplarına farkındalık kazandırabilme açısından desteklenmesi gerektiği düşünülmektedir.

Anahtar kelimler: Disiplinler arası çalışmalar, öğrenciler, sağllk eğitimi

Sorumlu Yazar: Hatice Abaoğlu, Hacettepe Üniversitesi, Sağlık Bilimleri Fakültesi, Ergoterapi Bölümü, Sıhhiye, ANKARA. Tel: 03123052560 E-mail: haticeabaoglu@ hacettepe.edu.tr 


\title{
The Perception of University Students on Team Work
}

\section{Investigation of the Perception of University Students in Health Sciences on Interdisciplinary Team Work}

\author{
Hatice Abaoğlu ${ }^{1}$, Özge Buket Cesim ${ }^{1}$, Sinem Kars ${ }^{1}$, Semin $_{\text {Akel }}{ }^{1}$ \\ ${ }^{1}$ Hacettepe University, Faculty of Healh Sciences, Occupational Therapy Department, Ankara
}

\begin{abstract}
Objectives: The aim of this study was to evaluate the perception of university students studying in the field of health sciences on interdisciplinary teamwork.

Materials and Methods: 265 university students of health sciences field aged between 18-25 participated in the study. Demographic characteristics of individuals, including age, gender, department and grade were recorded. In the study, Interdisciplinary Study Questionnaire which was adapted from 'the Interdisciplinary Education Perception Scale' was used as a data collection tool.

Results: Most of the individuals stated that they knew what the interdisciplinary study meant and it would be useful; they knew which professions were associated with their own profession; they would like to have fieldwork with students of other professions; and they wouldn't hesitate to ask for help from professionals outside their own field. It was found that individuals thought people in their profession did not consider themselves superior to other occupational groups; they were in good relationship with and interacted with those belonged to other professions; they tried to understand their skills and contributions and they wanted to share information and resources with them. Most of the individuals were of the opinion that the individuals in their profession were well-educated although had limited professional competence and autonomy.

Conclusions: According to these results, it was concluded that students who study in the field of health sciences found interdisciplinary study important and useful. It is thought that individuals should be supported in terms of competence, autonomy and the awareness of the professional groups they will work with after graduation.
\end{abstract}

Keywords: Interdisciplinary studies, students, health education

Corresponding Author: Hatice Abaoğlu, Hacettepe University, Faculty of Health Sciences, Occupational Therapy Department, Sihhiye, ANKARA. Phone: 03123052560 E-mail: haticeabaoglu @ hacettepe.edu.tr 


\section{Giriș}

doi: $10.21020 / h u s b f d .479846$

İnterdisipliner ekip çalışması, "tamamlayıcı geçmişleri ve becerileri olan, ortak sağlık hedeflerini paylaşan ve hasta bakımını değerlendiren veya planlayan uyumlu bir fiziksel ve zihinsel çaba harcayan iki veya daha fazla sağlık çalışanını içeren dinamik bir süreç” olarak tanımlanabilir. $\mathrm{Bu}$, birbirine bağımlı işbirliği, açık iletişim ve ortak karar alma mekanizması yoluyla gerçekleştirilir (Nancarrow ve diğ., 2013). İnterdisipliner ekip çalışması, iyi iletişim ve diğer ekip üyelerinin rollerini anlama ile ilgili tüm profesyonellerin etkileşimli çabalarıyla sağlanır. Sürece katılan herkes, diğerlerinin katkılarını dikkate alır (Courtenay, Nancarrow ve Dawson, 2013).

Ekip çalışmaları uygulamaları, sağlık hizmetlerinde giderek artmakta ve hizmet uygulamalarının önemli bir parçası haline gelmektedir. Kaliteli sağlık hizmeti sunmak için, farklı uzmanlığa sahip profesyonellerin birlikte çalışması önerilmektedir. Araştırmalar, etkili ekip çalışmasının, daha iyi sağlık sonuçları ve etkin maliyet ile ilişkili olduğunu ortaya koymaktadır. Ayrıca etkin ekip çalışması yapılabildiğinde, daha iyi kararlar alındığı, karmaşık görevlerle daha iyi başa çıkıldığı, daha entegre bakım planları üretildiği ve daha koordineli çalış1ldığ1 gösterilmiştir (Valentine, Nembhard ve Edmondson, 2015; West ve Lyubovnikova, 2013; Al Sayah, Szafran, Robertson, Bell ve Williams, 2014). İnterdisipliner ekip çalışmasının eksikliğinin, sağlık alanında riskli ve olumsuz sonuçlara neden olabileceği düşünülmektedir. Bununla birlikte, hasta güvenliği konusundaki endişeler de eğitim programlarında profesyoneller arasındaki ekip çalışmasını güçlendirmek için büyük bir itici güç olarak görülebilir. Buna ek olarak, profesyoneller arasındaki ekip çalışmasının iyileştirilmesi ile sağlık profesyonellerinin iş doyumu ve refah düzeyini artırabileceği önerilmektedir (Aase, Aase ve Dieckmann, 2013).

Sağlık hizmetlerinde interdisipliner ekip çalışması, farklı meslek gruplarının hasta bakımı üzerine uzmanlık, bilgi ve becerilerini paylaşarak birlikte çalıştığı karmaşık bir süreçtir. Farklı becerilerin bir arada olması, hizmet ortamları ve organizasyonu, bireysel ilişkiler ve yönetim yapıları gibi çok sayıda faktörden etkilenmesi, ekip çalışmasının yürütülmesini zorlaştırmaktadır. Sağlık eğitimi alanlarında diğer disiplinlerle etkin bir şekilde çalışmak, sağlık uygulayıcıları için önemli ve gerekli bir beceridir. Bu nedenle, mezunlarını mesleki uygulama için hazırlayan akademik kurumların, etkin işbirliği için gerekli becerilerin geliştirilmesini kolaylaştıran öğrenme firsatları yaratmaları beklenmektedir. Üniversiteler, sağlık hizmet ekibinin etkin bir üyesi olabilecek mezunlar yetiştirmeyi hedeflemektedir. Sağlık çalışanları, etkili ekip çalışması ve iletişim becerileri ile çeşitli klinik ortamlarda hem işbirliğine dayalı hem 
de özerk olarak çalışabilmelidir (Nancarrow ve diğ., 2013; Wellmon, Gilin, Knauss ve Linn, 2012; Lapkin, Levett-Jones ve Gilligan, 2013).

Son yıllarda, sağlık eğitimleri alanındaki profesyoneller arası ekip çalışması dünya çapında ilgi gören bir konu haline gelmiştir. Bununla birlikte, sağlık alanlarının ekip çalışmasını kendi eğitim programlarına dahil etme derecesi hakkında çok az şey bilinmektedir (Aase ve diğg., 2013). Bu araştırma, sağlık bilimleri alanında farklı bölümlerde öğrenim gören üniversite öğrencilerinin interdisipliner ekip çalışmasına bakış açılarını değerlendirmek amacıyla planlanmiştır.

\section{Gereç ve Yöntem}

Araştırmaya sağlık bilimleri alanında öğrenim gören ve yaşları 18-25 yaş aralığında olan 265 üniversite öğrencisi katıldı. Öğrencilerin yaş, cinsiyet, bölüm ve sınıf bilgilerini içeren demografik özellikleri kaydedildi. Araştırma Helsinki Bildirgesine uygun olarak yürütüldü ve katılımcılara araştırma hakkında ayrıntılı bilgi verildikten sonra aydınlatılıış onam alındı.

Araştırmaya dahil edilen bireylere Luecht, Madsen, Taugher ve Petterson (1990) tarafından kişinin kendi mesleğiyle ilgili algısını ve bu mesleğin başkalarıyla olan ilişkisini değerlendirmek amaciyla geliştirdiği İnterdisipliner Eğitim Algısı Ölçeği’nden (The Interdisciplinary Education Perception Scale) uyarlanarak araştırmacılar tarafından oluşturulan 'İnterdisipliner Çalışma Anketi' uygulandı. Anket "Katılıyorum”, "Biraz katılıyorum" ve "Katılmıyorum" şeklinde cevaplanan 3'lü Likert tipinde toplam 27 farklı sorudan oluşmaktadır.

Verilerin analizi için Sosyal Bilimler için İstatistik Paket Programı 21 (SPSS-Statistical Packages for the Social Sciences) kullanıldı. Bireylerin yaş dağılımları ortalama ve standart sapma olarak verildi. Cinsiyet, bölüm ve sınıfı içeren diğer demografik değişkenler frekans ve yüzde dağılımı verildi. Anket yönteminden elde edilen veriler her bir soru için tanımlayıcı istatistiksel yöntemlerden frekans ve yüzde dağılımları kullanılarak çözümlendi. Veriler tablolaştırılarak incelendi.

\section{Bulgular}

Çalışmaya dahil edilen bireylerin 70’i erkek (\%26), 195'i kadındı (\%74). Öğrenim gördükleri bölümlere göre öğrencilerin dağılımı incelendiğinde; 91 kişi Ergoterapi $(\% 34,3), 91$ kişi Fizyoterapi (\%34,3), 42 kişi Dil ve Konuşma Terapisi (\%15,8), 17 kişi Odyoloji (\%6,4), 14 kişi Beslenme ve Diyetetik $(\% 5,3)$ ve 10 kişi Çocuk Gelişimi $(\% 3,8)$ bölümündeydi. 
Öğrencilerin 98'i (\% 37) birinci sınıf, 64'ü (\%24,2) ikinci sınıf, 62'si (\% 23,4) üçüncü sınıf ve 41’i (\% 15,5) dördüncü sinıftaydı (Tablo 1).

Tablo 1. Demografik özellikler.

\begin{tabular}{lll}
\hline Yaş (X+SS) & $20,36 \pm 2,61$ & \\
\hline Cinsiyet & n & \% \\
Kadın & 195 & 73,6 \\
Erkek & 70 & 26,4 \\
\hline Bölüm & $\mathbf{n}$ & $\mathbf{\%}$ \\
Ergoterapi & 91 & 34,3 \\
Fizyoterapi & 91 & 34,3 \\
Dil ve Konuşma Terapisi & 42 & 15,8 \\
Odyoloji & 17 & 6,4 \\
Beslenme ve Diyetetik & 14 & 5,3 \\
Çocuk Gelişimi & 10 & 3,8 \\
\hline Sınıf & $\mathbf{n}$ & $\mathbf{\%}$ \\
Birinci & 98 & 37,0 \\
İkinci & 64 & 24,2 \\
Üçüncü & 62 & 23,4 \\
Dördüncü & 41 & 15,5
\end{tabular}

İnterdisipliner Çalışma Anketi'nden elde edilen sonuçların frekans ve yüzde dağılımı Tablo 2'de verilmiştir. Buna göre bireylerin çoğu, interdisipliner çalışmanın ne anlama geldiğini bildiğini (\% 64,5) ve yararlı olacağına inandığını (\% 71,7), meslek grubunun ilişkide olabileceği diğer meslek gruplarıyla ilgili bilgisi olduğunu (\% 50,6), diğer meslek gruplarıyla uygulama ve saha çalışması yapmak istediğini $(\%$ 76,2) ve çözemediği bir problemi başka meslek gruplarına danışmaktan kaçınmadığını (\% 71,3) belirtti. Bireylerin çoğunlukla, mesleğindeki kişilerin kendilerini diğer meslek gruplarından üstün görmedikleri $(\% 68,7)$, onlarla iyi ilişkide $(\% 50,9)$ ve etkileşim halinde oldukları $(\% 70,2)$, birlikte çalışabildiklerini $(\% 78,5)$ onların beceri ve katkılarını anlamaya çaba gösterdikleri $(\% 52,8)$, bilgi ve kaynak paylaşmayı istediklerini $(\%$ 58,1) düşündükleri tespit edildi. Buna karşın bireylerin çoğu, mesleğindeki kişilerin iyi eğitimli olduklarını düşünürken $(\% 55,1)$ mesleki yetkililik (\% 40) ve otonomi (\% 47,9) konusunda kısıtlılıkları olduğu, diğer meslekten kişilerin kendi mesleği 
hakkında bilgi sahibi olmadığı $(\%$ 47,9) görüşündeydi. Bunların yanı sıra bireyler mesleklerinin diğer meslek gruplarından üstün olmadığını (\% 50,2), hiyerarşinin interdisipliner çalışmayı olumsuz etkilediğini (\% 47,9) düşünüyordu.

Tablo 2. İnterdisipliner Çalışma Anketi sonuçları.

\begin{tabular}{|c|c|c|c|}
\hline İnterdisipliner Çalışma Anketi & Katılıyorum & $\begin{array}{l}\text { Biraz } \\
\text { Katılıyorum }\end{array}$ & Katılmıyorum \\
\hline $\begin{array}{l}\text { 1. Müfredatımızda interdisipliner çalışmaya } \\
\text { yönelik ders/derslerim vardır. }\end{array}$ & $\% 38,5$ & $\% 42,3$ & $\% 19,2$ \\
\hline $\begin{array}{l}\text { 2. İnterdisipliner çalışmanın ne anlama } \\
\text { geldiğini biliyorum. }\end{array}$ & $\% 64,5$ & $\% 24,2$ & $\% 11,3$ \\
\hline $\begin{array}{l}\text { 3. İnterdisipliner çalışmanın yararlı olacağına } \\
\text { inanıyorum. }\end{array}$ & $\% 71,7$ & $\% 21,5$ & $\% 6,8$ \\
\hline $\begin{array}{l}\text { 4. Hocalarım interdisipliner çalışmaya önem } \\
\text { verir. }\end{array}$ & $\% 55,5$ & $\% 29,8$ & $\% 14,7$ \\
\hline $\begin{array}{l}\text { 5. İnterdisipliner çalışmanın multidisipliner } \\
\text { çalışmadan farkını biliyorum. }\end{array}$ & $\% 37,7$ & $\% 29,4$ & $\% 32,8$ \\
\hline 6. Mesleğimdeki kişiler iyi eğitimlidir. & $\% 55,1$ & $\% 34$ & $\% 10,9$ \\
\hline $\begin{array}{l}\text { 7. Mesleğimdeki kişiler diğer meslek } \\
\text { gruplarıyla çalışabilir. }\end{array}$ & $\% 78,5$ & $\% 18,9$ & $\% 2,6$ \\
\hline $\begin{array}{l}\text { 8. Mesleğim diğer meslek gruplarından } \\
\text { üstündür. }\end{array}$ & $\% 16,6$ & $\% 33,2$ & $\% 50,2$ \\
\hline $\begin{array}{l}\text { 9. Diğer meslek gruplarıyla uygulama ve saha } \\
\text { çalışması yapmak isterim. }\end{array}$ & $\% 76,2$ & $\% 19,6$ & $\% 4,2$ \\
\hline $\begin{array}{l}\text { 10. Mesleğimdeki kişiler fazlasıyla otonomi } \\
\text { (özerklik) gösterir. }\end{array}$ & $\% 13,2$ & $\% 38,9$ & $\% 47,9$ \\
\hline $\begin{array}{l}\text { 11. İnterdisipliner çalışmada hiyerarşi olmas1 } \\
\text { interdisipliner çalışmayı olumsuz etkiler. }\end{array}$ & $\% 47,9$ & $\% 21,9$ & $\% 30,2$ \\
\hline $\begin{array}{l}\text { 12. Diğer meslekteki kişiler benim yaptığım } \\
\text { çalışmaya saygı gösterir. }\end{array}$ & $\% 37,4$ & $\% 42,3$ & $\% 19,2$ \\
\hline $\begin{array}{l}\text { 13. Mesleğimdeki kişiler kendi amaçları için } \\
\text { olumlu yaklaşımda bulunur. }\end{array}$ & $\% 55,5$ & $\% 34,3$ & $\% 9,8$ \\
\hline $\begin{array}{l}\text { 14. Mesleğimdeki kişiler kendi amaçları için } \\
\text { interdisipliner çalışmayı kullanır. }\end{array}$ & $\% 46,8$ & $\% 38,1$ & $\% 14,7$ \\
\hline $\begin{array}{l}\text { 15. Mesleğimdeki kişiler diğer meslek } \\
\text { gruplarıyla işbirliği yapmak zorundadır. }\end{array}$ & $\% 57,7$ & $\% 30,9$ & $\% 11,3$ \\
\hline
\end{tabular}




16. Mesleğimdeki kişiler yaptıkları iş ve katkı $\quad \%$ 62,6 $\quad \%$ 29,1 $\quad$ \% 8,3

konusunda olumlu düşünceye sahiptir.

17. Benim mesleğimdeki kişiler diğer $\quad \%$ 70,2 $\quad \% 26,8 \quad \% 3$
meslekteki kişilerle etkileşim halindedir.

18. Meslek grubumun ilişkide olabileceği diğer $\quad \%$ 50,6 $\quad \%$ 41,5 $\quad \%$ 7,9 meslek gruplarıyla ilgili bilgim var.

19. Çözemediğim bir problemi başka meslek $\%$ 71,3 $\quad \%$ 24,5 4,2 gruplarına danışmaktan kaçınmam.

20. Diğer meslekteki kişilerin benim mesleğim $\quad \%$ 12,5 $\quad \%$ 39,6 $\quad \%$ 47,9

hakkında bilgisi vardır.

\begin{tabular}{|c|c|c|c|}
\hline $\begin{array}{l}\text { 21. Mesleğimdeki kişiler birbirinin profesyonel } \\
\text { görüşüne güvenir. }\end{array}$ & $\% 43$ & $\% 42,6$ & $\% 14,3$ \\
\hline $\begin{array}{l}\text { 22. Mesleğimdeki kişiler kendini diğer meslek } \\
\text { gruplarından üstün görür. }\end{array}$ & $\% 7,5$ & $\% 23,8$ & $\% 68,7$ \\
\hline $\begin{array}{l}\text { 23. Mesleğimdeki kişiler diğer meslek } \\
\text { gruplarının beceri ve katkılarını anlamaya çaba } \\
\text { gösterir. }\end{array}$ & $\% 52,8$ & $\% 38,5$ & $\% 8,7$ \\
\hline 24. Mesleğimdeki kişiler tamamen yetkilidir. & $\% 21,1$ & $\% 38,9$ & $\% 40$ \\
\hline $\begin{array}{l}\text { 25. Mesleğimdeki kişiler diğer meslek } \\
\text { gruplarıyla iyi ilişkidedir. }\end{array}$ & $\% 50,9$ & $\% 39,2$ & $\% 9,8$ \\
\hline $\begin{array}{l}\text { 26. Diğer meslekteki kişiler benim } \\
\text { mesleğimdeki kişilerden tavsiye alır. }\end{array}$ & $\% 38,9$ & $\% 38,1$ & $\% 23$ \\
\hline $\begin{array}{l}\text { 27. Mesleğimdeki kişiler diğer kişilerle bilgi ve } \\
\text { kaynak paylaşmayı ister. }\end{array}$ & $\% 58,1$ & $\% 32,8$ & $\% 9,1$ \\
\hline
\end{tabular}

\section{Tartışma ve Sonuçlar}

Bu çalışmada sağlık bilimleri alanında farklı bölümlerde öğrenim gören üniversite öğrencilerinin interdisipliner ekip çalışmasına olan bakış açıları incelenmiştir. Dünya Sağlık Örgütü (2010) sağlık eğitim programlarının interdisipliner çalışmaları destekleyici içeriklere sahip olması gerektiğini vurgulamaktadır. Çalışmamıza dahil edilen öğrencilerin çoğunluğu müfredatlarında interdisipliner çalışmaya yönelik derslerin olduğunu ifade etmiştir. Hall ve Weaver (2001) ekip çalışmasının etkin olması için tüm sağlık profesyonellerinin ekip çalışması hakkında eğitim alması gerektiğini belirtmektedir. Çalışmamızda ise, sağlık bilimleri öğrencilerinin interdisipliner çalışmanın önemi açısından farkındalığa sahip olduğu belirlendi. Ayrıca; sağlık bilimleri öğrencileri, öğretmenlerinin interdisipliner çalışmaya önem verdiğini 
de belirtti. Bu bulgular doğrultusunda, sağlık bilimleri öğrencilerinin lisans eğitimi sırasında ekip çalışması ve önemi konusunda bilgilendiklerini söyleyebiliriz.

Literatürde, etkili bir interdisipliner ekip çalışmasında; interdisipliner çalışma ekibinin iletişim ve işbirliği açısından hiyerarşik olarak aynı seviyede olduğu ve ekip üyeleri arasında güven, bilgi, karşılıklı saygı, iletişim, iş birliği, anlayış, koordineli çalışma ve eşit sorumluluk olmas1 gerektiği belirtilmektedir (Behm ve Gray, 2011; Domaç ve diğ., 2014; Jacelon, 2011). Çalışmamıza dahil edilen sağlık bilimleri öğrencileri çoğunlukla interdisipliner çalışmada hiyerarşi olmasının interdisipliner çalışmayı olumsuz etkileyeceğini belirtti. Ayrıca; kendi meslek grubundaki kişilerin kendilerini diğer meslek gruplarından üstün görmediğini (hiyerarşik olarak aynı seviye), diğer meslek gruplarına danışmaktan kaçınmadığını (iletişim) ve diğer meslek gruplarının beceri ve katkılarını anlamaya çaba gösterdiğini (iş birliği) de belirtildi. Benzer şekilde, öğrencilerin çoğunluğu, diğer meslek gruplarının kendi mesleği hakkında bilgisi olduğunu ve kendi meslek grubuna danışacağını ifade etti. Bu bulgular doğrultusunda, sağlık bilimleri öğrencilerinin interdisipliner ekip çalışması için gerekli olan özelliklere sahip olduğu düşünülmektedir.

White ve ark (2013) sağlık bilimleri öğrencilerinin eğitimleri sırasında interdisipliner çalışmalara katılmaları, interdisipliner çalışmalar konusunda kongrelere yönlendirilmeleri ve diğer meslek grupları ile iletişim kurabilecekleri ortamların düzenlenmesi gerektiğini belirtmektedir. Çalışmamızın önemli bulgularından birisi de, çalışmamıza dahil edilen sağlık bilimleri öğrencilerinin çoğunlukla diğer meslek gruplarıyla uygulama ve saha çalışması yapmak istemesidir. Buna karşın, öğrenciler mesleklerindeki kişilerin mesleki yetkililik ve otonomi konusunda kısıtlılıkları olduğu, diğer meslekten kişilerin kendi meslekleri hakkında bilgi sahibi olmadığı görüşündeydi. Sağlık bilimleri öğrencilerinin uygulama ve saha çalışmaları konusunda istekli oldukları saptanmıştır. Bu nedenle, interdisipliner çalışmayı deneyimleyebilecekleri ve kendi mesleklerini tanıtarak yetkililik ve otonomi geliştirebilecekleri kongre, vaka çalışmaları, vb. aktivitelerin düzenlenmesi gerektiği düşünülmektedir. Mickan (2005) interdisipliner çalışmanın önemine inanan sağlık çalışanlarının ve interdisipliner çalışmaların, hastalar için olumlu sonuçlar ortaya çıkaracağını belirtmiş̧tir. Dolayısıyla, bu aktivitelerin etkinliği uygulama ve saha çalışmaları sırasında sağlı bilimleri öğrencilerinin hastalar üzerindeki etkileri değerlendirilerek belirlenebilir. Böylece, interdisipliner çalışmayı engellemesi muhtemel faktörlerin de eğitim ve uygulama imkanları ile birlikte ortadan kalkacağı düşünülmektedir.

Sonuç olarak, sağlık bilimleri alanında farklı bölümlerde öğrenim gören üniversite öğrencilerinin interdisipliner ekip çalışmasına bakış açılarını değerlendirdiğimiz çalışmamızda 
sağlık bilimleri öğrencilerinin interdisipliner ekip çalışması hakkında olumlu bir bakış açısına ve interdisipliner çalışma becerisine sahip olduğu söylenebilir. Sonuçların, nitel analiz yöntemlerini ve interdisipliner çalışmanın farklı boyutlarını kapsamlı bir şekilde ele alan ileri çalışmalarla desteklenebileceği düşünülmektedir. 


\section{Kaynakça}

Aase, I., Aase, K., \& Dieckmann, P. (2013). Teaching interprofessional teamwork in medical and nursing education in Norway: A content analysis. Journal of Interprofessional Care, 27(3), 238245.

Al Sayah, F., Szafran, O., Robertson, S., Bell, N. R., \& Williams, B. (2014). Nursing perspectives on factors influencing interdisciplinary teamwork in the Canadian primary care setting. Journal of clinical nursing, 23(19-20), 2968-2979.

Behm, J., \& Gray, N. (2011). Interdisciplinary rehabilitation team. Rehabilitation nursing: A contemporary approach to practice, 51-62.

Courtenay, M., Nancarrow, S., \& Dawson, D. (2013). Interprofessional teamwork in the trauma setting: a scoping review. Human resources for health, 11(1), 57.

Domaç, S., Fidan, M. B., Sobacı, F., Yıldırım, A., Soydaş, P., \& Özkent, T. (2014). Meslekler Arası Eğitimin Yükseköğretim Müfredatına Dâhil Edilmesinin Önemi. Yükseköğretim Dergisi, 4(1), 9-13.

Dünya Sağlik Örgütü (2010). Framework for action on interprofessional education \& collaborative practice. Geneva: Department of Human Resources for Health.

Hall, P., \& Weaver, L. (2001). Interdisciplinary education and teamwork: a long and winding road. Medical education, 35(9), 867-875.

Jacelon, C. (2011). Health care, rehabilitation, and rehabilitation nursing. The specialty practice of rehabilitation nursing, 6 .

Lapkin, S., Levett-Jones, T., \& Gilligan, C. (2013). A systematic review of the effectiveness of interprofessional education in health professional programs. Nurse education today, 33(2), 90102.

Luecht, R. M., Madsen, M. K., Taugher, M. P., \& Petterson, B. J. (1990). Assessing professional perceptions: Design and validation of an interdisciplinary education perception scale. $J$ Allied Health, 19(2), 181-191.

Mickan, S. M. (2005). Evaluating the effectiveness of health care teams. Australian Health Review, 29(2), 211-217.

Nancarrow, S. A., Booth, A., Ariss, S., Smith, T., Enderby, P., \& Roots, A. (2013). Ten principles of good interdisciplinary team work. Human resources for Health, 11(1), 19.

Valentine, M. A., Nembhard, I. M., \& Edmondson, A. C. (2015). Measuring teamwork in health care settings: a review of survey instruments. Medical care, 53(4), e16-e30.

Wellmon, R., Gilin, B., Knauss, L., \& Linn, M. I. (2012). Changes in student attitudes toward interprofessional learning and collaboration arising from a case-based educational experience. Journal of Allied Health, 41(1), 26-34.

West, M. A., \& Lyubovnikova, J. (2013). Illusions of team working in health care. Journal of health organization and management, 27(1), 134-142.

White, M. J., Gutierrez, A., McLaughlin, C., Eziakonwa, C., Newman, L. S., White, M., Thayer, B., Davis, K., Williams, M., Asselin, G. (2013). A pilot for understanding interdisciplinary teams in rehabilitation practice. Rehabilitation Nursing, 38(3), 142-152. 